Lorentz, P., Ferguson, C. J., \& Schott, G. (2015). Editorial: The experience and benefits of game playing. Cyberpsychology: Journal of Psychosocial Research on Cyberspace, 9(3), article 1. doi: 10.5817/CP20153-1

\title{
Editorial: The experience and benefits of game playing
}

\author{
Pascaline Lorentz ${ }^{1}$, Christopher J. Ferguson², Gareth Schott ${ }^{3}$ \\ ${ }^{1}$ Masaryk University, Brno, The Czech Republic \\ 2 Stetson University, DeLand, Florida, United States \\ ${ }^{3}$ University of Waikato, Hamilton, New Zealand
}

\section{Introduction}

Now that video games have permeated daily life across the globe on computers, consoles and pocket devices, they call for a more comprehensive-and accurate-understanding of their role in society. Psychological research into the impact of games upon players was initiated more than fifteen years ago, with researches devoted to uncovering the alleged negative impact of game playing in response to politically driven moral panics. The focus and dominance of experimental 'effects' research has given rise to a need for further research to balance what is sometimes seen as moral crusades associated with causation studies to articulate the more mundane, less contentious existence of games as a significant leisure activity for billions of individuals who repeatedly play them for entertainment and fun.

That is not to say that public disputes over what some perceive as the harmful nature of games have disappeared or lost their significance, as they are reignited on a regular basis by media coverage of school or mass shootings. Such coverage often serves to draw out the long-term judgments of individual politicians, campaigners and researchers with little primary research to bring to the debate. A recent example of this is the interview conducted with Pr. Phil Zimbardo on the BBC in May 2015 (watch here). Despite Dr. Andrew Przybylski ensuing astute deconstruction and critique of Zimbardo's claims, the prejudices against video gaming often prove resistant to reevaluation. In this vein, the American Psychological Association also very recently revealed results, from their Task Force on Violent Media in 2013 that claimed a 'consistent' relation between aggression and playing violent video games (American Psychological Association, 2015). The emphasis quickly shifted, however, from problems with video games to problems with the task force for perceived conflicts of interest among the task force members and significant shortcomings of the meta-analysis performed which included only 18 studies and excluded numerous null studies (Wooford, 2015). This report again served to hinder progress by re-activating longstanding positions on the effects of video games shadowing work that has since been completed in many disciplines that outline beneficial effects of playing video games.

This special issue of Cyberpsychology entitled "The Experience and Benefits of Game Playing" reflects the efforts of a range of European, American and Australian researchers who place the experience of playing video games at the core of their reflective work. Studies on video gaming can be differentiated on the basis of the extent to which the research positions games at the heart of their work, in addition to the extent to which research gives attention to the capacities and thinking of the game player to be able to offer perspectives on player experience. This approach to research is evident in all articles included in this special issue.

The special edition also sought to widen the research disciplines that could submit research in order to reflect how games currently constitutes an object of study for a wide range of disciplines-including (but not limited to) psychology, media studies, sociology, philosophy, and computer and organizational sciences. The intent was to present research with cross-disciplinary relevance to suggest the kinds of connections that can be made across a wider body of literature with a broader range of research interests reflecting an expansive range of video game texts. 


\section{Game Playing: As a Conventional Leisure Activity}

With its overwhelming number of enthusiasts across the globe, video gaming has become a daily activity and familiar part of the cultural fabric of home life, but also mobile life with the increasing capacities of smart phones (ESA, 2015; Brand et al., 2013; IFSE, 2012). Video gaming is now a mainstream leisure or recreational activity (Oswald et al. 2014; Lorentz, 2015) to which leisure studies scholarship is consequently situated to better analyze and understand this practice. The disciplinary areas of therapeutic recreation or recreational therapy emerged in the 1980s giving consideration to the utilization of leisure to improve life experience of practitioners. Among the developed body of research from leisure studies, Kleiber, Hutchinson and Williams (2002) demonstrated that leisure activities can operate as a selfprotection, self-restoration and a personal transformation mechanism for individuals facing traumatic or challenging life changes. Video gaming was initially considered a "passive leisure" activity due to its close association with other audio-visual mediums, such as TV watching (Holder, Coleman and Sehn, 2009), but has since become understood as distinct from other more traditional indoor-screen recreational activities and their related effects on wellbeing. Video game play as a leisure activity possesses distinct characteristics associated with agency, challenge and progression that necessitate an understanding of the game systems that contain activity.

Since Kleiber's study-which concentrated on post-traumatic experiences-video gaming has proved to be efficient in a number of therapeutic contexts (HC LI et al, 2011). Furthermore, the Videogames and Wellbeing report published in 2013 (Johnson et al.) has mapped the main benefits of video gaming in people's general wellbeing as an activity that triggers positive emotional impact (emotional stability, self-esteem, optimism, vitality, resilience), positive functioning (engagement, positive relationships, competence \& achievement, self-acceptance, personal growth), and positive social functioning (social coherence, social integration, social capital). This review was followed by another review detailing the Benefits of Video Games (Granic et al., 2014) in the American Psychologist in which researchers identified the different cognitive, motivational, emotional and social values of video gaming. Video games can, indeed, be seen as a "context for applied cognition" as they provide "cognitive puzzles," "enhance cognitive skills" (Blumberg \& Fish, 2013, p.4) and encourage children to take initiative (Adachi \& Willoughby, 2013)-as "they require cumulative effort over time to achieve the goal of completing the game" (p.157). Blumberg and Fish (2013) also advocate that developmental psychologists should involve themselves in the design of games due to the role of video gaming in cognitive development of children.

\section{Challenges of Cross-Disciplinary Research}

No one discipline is equipped to address all the topics raised by games as a media and playing as a practice. To avoid this pitfall, this special issue followed prior recommendations (Oswald, Prorock and Murphy, 2014, p.123) to develop and encourage cross-disciplinary publications.

This special issue aimed to offer a platform for a diverse range of researchers from all fields to present their work for our discipline to consider and reflect upon. Gathering three guest editors from three distinct disciplines highlighted foreseeable differences in approach to theory and research. The editors of this issue comprise of Christopher Ferguson, a clinical psychologist; Gareth Schott, who holds a PhD in psychology but has spent the last 15 years researching as a game studies scholar; and Pascaline Lorentz, a sociologist who worked in a psychology department. As a result of a call for papers reflecting these different areas of interest, articles were submitted for this issue from psychology, media studies, gender studies, philosophy, history, computer science and management science.

One of the first issues that this publication had to confront was the different emphasis and importance that separate disciplines attached to distinct aspects of research inquiry. Respecting the variability of disciplines, editors decided to transfer freedom to authors to structure and present their research most suitable to the nature of the research. Working on a cross-disciplinary publication is an opportunity to question the homogeneity of our own forms of communication that have come to signify the quality of the scientific debate (Oswald, Prorock and Murphy, 2014, p.123). Thus, this issue offers a tapestry of works from different disciplines that hopefully combine to provide a sense of a bigger picture as to how many researchers conceptualize and articulate the nature of game playing. In doing so, we offer a distinctive range of papers, each offering a particular way of looking at the video game practice that produce different conclusions. These articles all coincide in positing the player at the heart of their study.

This special issue only saw the light of day thanks to all reviewers' kind participation and hard work. The editors of this issue wish to stress the importance of the review process for the contributing authors. Writing a "good" review is a delicate exercise that requires a sharp eye, a way with words and willingness 
to extend their knowledge via different approaches. The reviewers of this issue came from different parts of the world and varied disciplines; but all delivered genuine advice and comments in support of authors. We dearly and deeply thank all participants who agreed to give up their time, their energy, and their advice to help improve publications.

\section{The Papers of This Issue}

In the end, this special issue aims to identify where the benefits of game playing lie beginning with Turkay and Adolfino's work on customization and motivation in Massively Multiplayer Online Game Lord of the Rings (Turbine, 2007) in which they focus on how making playing of a game a more personal experience increases the motivation to play and in doing so drives players to reiterate their enjoyable experiences.

Among manifold utilizations of game texts, we find that some players are able to perform their sexuality more freely in game worlds. Krobova and her colleagues narrow their focus to players of two game titles Dragon Age and Mass Effect both developed by BioWare-an inclusive LGBT developer. Findings show players adopt three distinct strategies-imaginative play, stylized performance and role-playing. They astutely bring the debate for readers to reflect upon the possibility of creating a queer video game segment of the industry.

DeByl presents a framework for affective elements in game design. Supported by her extensive experience in this field, she thoroughly surveys the nascent scholarship on affective game design to draw a solid picture of current possibilities useful to any game researcher/developer.

Similarly, Kaufman and Flanagan present their concept of "embedded design" applied to two games. This tool enables the creation and development of games which support social justice by providing a better chance for players to increase their social awareness with subtlety and finesse.

These design tools would please Oravec who pinpoint the downsides of gamification in the workplace. Gamification at work, like at school, can obviously have positive impacts on cognitive skills and wellbeing of workers. Yet, this leverage includes potential abusive utilizations. By condemning the exacerbation of gamified applications in the work life, Oravec warns the scientific community against the foreseeable issues.

These articles gather important directions for the future of video gaming experiences. This leisure activity is thus becoming more personal, more meaningful, more fulfilling while seeking for the creation of a better world where social justice, respect and tolerance pave the way to a different range of experiences.

\section{Issue Content}

Article 1:

Editorial: The experience and benefits of game playing

Pascaline Lorentz, Christopher J. Ferguson and Gareth Schott

doi: $10.5817 / C P 2015-3-1$

Article 2:

The effects of customization on motivation in an extended study with a massively multiplayer online roleplaying game

Selen Turkay and Sonam Adinolf

doi: $10.5817 /$ CP2015-3-2

Article 3:

Dressing Commander Shepard in pink: Queer playing in a heteronormative game culture

Tereza Krobová, Ondřej Moravec and Jaroslav Švelch

doi: $10.5817 /$ CP2015-3-3

Article 4:

A conceptual affective design framework for the use of emotions in computer game design Penny de Byl

doi: $10.5817 / C P 2015-3-4$ 
Article 5:

A psychologically "embedded" approach to designing games for prosocial causes Geoff Kaufman and Mary Flanagan

doi: $10.5817 /$ CP2015-3-5

Article 6:

\section{Gamification and multigamification in the workplace: Expanding the ludic dimensions of work and challenging the work/play dichotomy}

Jo Ann Oravec

doi: $10.5817 /$ CP2015-3-6

\section{References}

Adachi, P. J., \& Willoughby, T. (2013). Do video games promote positive youth development? Journal of Adolescent Research, 28, 155-165. http://dx.doi.org/10.1177/0743558412464522

American Psychological Association. (2015, August 13). APA review confirms link between playing violent video games and aggression [Press release]. Retrieved from

http://www.apa.org/news/press/releases/2015/08/violent-video-games.aspx

Blumberg, F. C., \& Fisch, S. M. (2013). Introduction: Digital games as a context for cognitive development, learning, and developmental research. New Directions for Child and Adolescent Development, 2013(139), 1-9. http://dx.doi.org/10.1002/cad.20026

Brand, J. E., Lorentz, P., \& Mathew, T. (2013). Digital Australia 2014. Everleigh: Interactive Games and Entertainment Association.

Entertainment Software Association. (2015). Essential facts about the computer and video game industry. United States.

Granic, I., Lobel, A., \& Engels, R. C. (2014). The benefits of playing video games. American Psychologist, 69, 66-78. http://dx.doi.org/10.1037/a0034857

Holder, M. D., Coleman, B., \& Sehn, Z. L. (2009). The contribution of active and passive leisure to children's well-being. Journal of Health Psychology, 14, 378-386.

http://dx.doi.org/10.1177/1359105308101676

Interactive Software Federation of Europe. (2012). Video Games in Europe. Brussels: Ipsos Media.

Johnson, D., Scholes, L., \& Carras, M. C. (2013). Videogames and wellbeing: A comprehensive review. Young and Well Cooperative Research Centre, Melbourne. Retrieved from

https://www.youngandwellcrc.org.au/wp-content/uploads/2014/03/Videogames_and_Wellbeing.pdf

Kleiber, D. A., Hutchinson, S. L., \& Williams, R. (2002). Leisure as a resource in transcending negative life events: Self-protection, self-restoration, and personal transformation. Leisure Sciences, 24, 219-235. http://dx.doi.org/10.1080/01490400252900167

Li, W. H., Chung, J. O., \& Ho, E. K. (2011). The effectiveness of therapeutic play, using virtual reality computer games, in promoting the psychological well-being of children hospitalised with cancer. Journal of Clinical Nursing, 20, 2135-2143. http://dx.doi.org/10.1111/j.1365-2702.2011.03733.x

Lorentz, P. (2015). Playing online massively multiplayer games: An encroaching passion? In P. Lorentz, D. Smahel, M. Metykova, \& M. F. Wright (Eds.), Living in the digital age: Self-presentation, networking, playing and participating in politics (pp. 148-161). Brno: Masaryk University Press.

Oswald, C. A., Prorock, C., \& Murphy, S. M. (2014). The perceived meaning of the video game experience: An exploratory study. Psychology of Popular Media Culture, 3, 110-126.

http://dx.doi.org/10.1037/a0033828 
Turbine. (2007). Lord of the Rings Online [PC Game]. Warner Bros. Entertainment Inc.

Wofford, T. (2015, August 8). APA says video games make you violent, but critics cry bias. Newsweak. Retrieved from http://www.newsweek.com/apa-video-games-violence-364394

\section{About Journal}

The Cyberpsychology: Journal of Psychosocial Research on Cyberspace is a web-based, peer-reviewed scholarly journal. The first peer-reviewed issue was published in September 2007. The journal is focused on social science research about cyberspace. It brings psychosocial reflections of the impact of the Internet on people and society. The journal is interdisciplinary, publishing works written by scholars of psychology, media studies, communication science, sociology, political science, nursing, ICT security, organizational psychology and also other disciplines with relevance to psychosocial aspects of cyberspace. The journal accepts original research articles, as well as theoretical studies and research meta-analyses. Proposals for special issues are also welcomed.

The journal is indexed with SCOPUS, ERIH PLUS, EBSCO Academic Search Complete, the Directory of Open Access Journals and the Czech Database of Scientific Journals.

The articles in Cyberpsychology: Journal of Psychosocial Research on Cyberspace are open access articles licensed under the terms of the Creative Commons Attribution Non-Commercial License which permits unrestricted, non-commercial use, distribution and reproduction in any medium, provided the work is properly cited.

\section{Editor}

Prof. David Smahel, M.Sc. et Ph.D., Faculty of Social Studies, Masaryk University, Czech Republic

E-mail: smahel(at)fss.muni.cz

\section{Associate Editor}

Prof. Kristian Daneback, Ph.D., University of Gothenburg, Sweden

E-mail: kristian.daneback(at)socwork.gu.se

\section{Guest Editors of Special Issue "The experience and benefits of game playing"}

Pascaline Lorentz, Masaryk University, Brno, Czech Republic

E-mail: Pascaline.lorentz(at)gmail.com

Christopher J. Ferguson, Stetson University, DeLand, Florida, United States

E-mail: cjfergus(at)stetson.edu

Gareth Schott, University of Waikato, Hamilton, New Zealand

E-mail: sgrsnaes(at)waikato.ac.nz

\section{Editor Assistant}

Lenka Dedkova, M.A., Faculty of Social Studies, Masaryk University, Czech Republic

E-mail: Idedkova(at)fss.muni.cz 


\section{Editorial Board:}

Prof. Kaveri Subrahmanyam, Ph.D., California State University, Los Angeles, USA

Prof. Herbert Hrachovec, Ph.D., University of Vienna, Austria

Prof. Dr. Micheline Frenette, Universite de Montreal, Canada

Prof. Alexander E. Voiskounsky, Ph.D., Lomonosov Moscow State University, Russia

Prof. Michael W. Ross, Ph.D., DrMedSc, MPH, MPHEd, University of Texas, Houston, USA

Prof. Petr Macek, CSc., Masaryk University, Czech Republic

Prof. Olle Findahl, World Internet Institute, Sweden

Prof. Jochen Peter, Ph.D., University of Amsterdam, Netherlands

Prof. Veronika Kalmus, Ph.D., University of Tartu, Estonia

Prof. Joshua Fogel, Ph.D., Brooklyn College of the City University of New York, USA

Prof. Gustavo S. Mesch, Ph.D., University of Haifa, Israel

Michelle Wright, Ph.D., Masaryk University, Czech Republic

Václav Štětka, Ph.D., Charles University, Czech Republic

Andra Siibak, Ph.D., University of Tartu, Estonia

Adjunct Prof. Birgit U. Stetina, Ph.D., University of Vienna, Austria

Lukas Blinka, Ph.D., Masaryk University, Czech Republic

\section{Advisory Board:}

Prof. Bente Traen, Ph.D., University of Oslo, Norway

Prof. Charles Ess, Ph.D., University of Oslo, Norway

Prof. Dr. Ilse Kryspin-Exner, University of Vienna, Austria

Prof. PhDr. Jan Jirák, Ph.D., Charles University, Czech Republic

Prof. Vasja Vehovar, Ph.D., University of Ljubljana, Slovenia

Prof. Larry D. Rosen, Ph.D., California State University, USA

Prof. Patricia M. Greenfield, Ph.D., University of California, USA

Prof. Peter K Smith, University of London, England

Prof. Nicola Döring, IImenau University of Technology, Germany

Prof. Kimberly Young, Ph.D., St. Bonaventure University, USA

Prof. Jos de Haan, Ph.D., Erasmus University, Netherlands

Prof. Zbyněk Vybíral, Ph.D, Masaryk University, Czech Republic

Prof. Monica Whitty, Ph.D., University of Leicester, UK

Prof. Alistair Duff, Ph.D., Edinburgh Napier University, Scotland

Assoc. Prof. Alfred Choi, Ph.D., Nanyang Technological University, Singapore

Prof. Thurasamy Ramayah, Universiti Sains Malaysia, Malaysia

Assoc. Prof. Neil Coulson, Ph.D., The University of Nottingham, UK

Assoc. Prof. Kenneth C. C. Yang, Ph.D., University of Texas at El Paso, USA

Assoc. Prof. Sun Sun Lim, Ph.D., National University of Singapore, Singapore

Prof. Sameer Hinduja, Ph.D., Florida Atlantic University, USA

Assoc. Prof. Jana Horáková, Ph.D., Masaryk University, Czech Republic

Assoc. Prof. Radim Polčák, Ph.D., Masaryk University, Czech Republic

Assoc. Prof. Pille Pruulmann-Vengerfeldt, Ph.D., University of Tartu, Estonia

Assist. Prof. Alexander Schouten, Ph.D., Tilburg University, Netherlands

Assist. Prof. Ewa S. Callahan, Ph.D., Quinnipiac University, USA

Assist. Prof. Regina van den Eijnden, Ph.D., Utrecht University, Netherlands

Assist. Prof. Veysel Demirer, Ph.D., Süleyman Demirel Üniversitesi, Turkey

PhDr. Ing. Petr Soukup, Charles University, Czech Republic

Janis Wolak, Ph.D., University of New Hampshire, USA

Francesca Romana Seganti, Ph.D., Sapienza University of Rome, Italy

Jeff Gavin, Ph.D., University of Bath, UK

Hana Macháčková, Ph.D., Masaryk University, Czech Republic

Michael Fenichel, Ph.D., New York, USA

Leslie Haddon, Ph.D., London School of Economics, UK

Monica Barbovschi, Ph.D., Masaryk University, Czech Republic

Jan Širůček, Ph.D., Masaryk University, Czech Republic 


\section{Publisher}

Masaryk University, Faculty of Social Studies

Jostova 10, 60200 Brno

Czech Republic

\section{Publication Schedule}

Twice per year (July and December) plus special issues

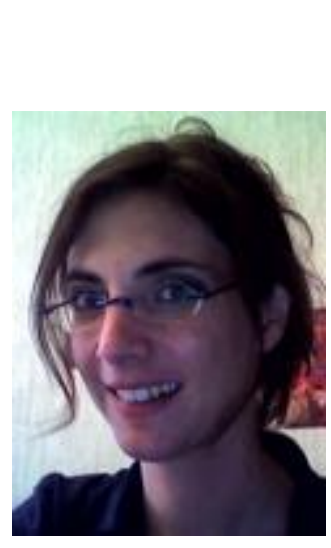

\section{About authors}

Pascaline Lorentz, PhD is a Postdoctoral Researcher working on online gaming at the Institute for Research on Children, Youth and Family at Masaryk University. Granted with an ENDEAVOUR Research Fellowship in 2011 she undertook a study documenting the social environment of an intense practice of virtual world attachments in Australia. Her doctoral research completed in 2012 at the University of Strasbourg in France

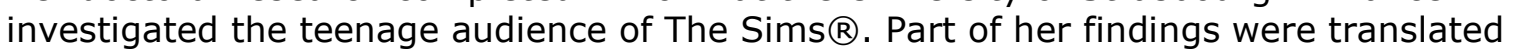
into English and published in a monograph, The Socializing Voyage of the Video Game Player, freely available for download.

In 2015, she was the main editor of the book Living in the Digital Age: Self-

Presentation, Networking, Playing, and Participating in Politics.

Follow her research activity: https://pascalinelorentz.wordpress.com/

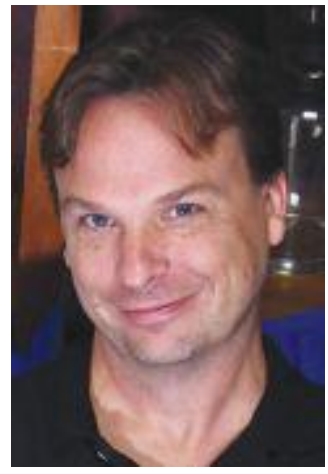

Christopher J. Ferguson, PhD is an Associate Professor and Chair of Psychology at Stetson University. He holds a Ph.D. in Clinical Psychology from the University of Central Florida. He has clinical experience particularly in working with offender and juvenile justice populations as well as conducting evaluations for child protective services. In 2013 he was awarded a Distinguished Early Career Professional Award from Division 46 (media psychology and technology) of the American Psychological Association. In 2014 he was named a fellow of the American Psychological Association through Division 1 (General Psychology, effective January, 2015).

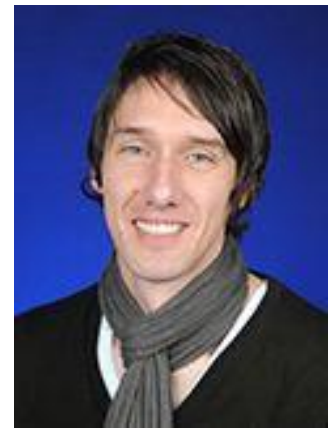

Gareth Schott holds a PhD in Psychology from the University of Wales, Cardiff (UK). $\mathrm{He}$ is currently a Senior Lecturer at the School of Arts, University of Waikato. He has been a principal investigator on two Royal Society of New Zealand: Marsden grants for research into players' experiences with videogames containing violent content. He has also conducted research on behalf of the NZ Office of Film and Literature Classification on the topic of parental understanding and experience of violence in videogames. He has published widely in the field of 'game studies' since its inception as an academic discipline in 2001. He is co-author of the book Computer Games: Text, narrative and play (published by Polity Press) and is currently working on a book entitled 'Violent Videogames: Rules, realism and effect' that will be published by Bloomsbury Press (New York) in 2015. He has also recently been appointed to the Film and Literature Review Board by the NZ Governor General for a three year term. 